\title{
Algunas consideraciones sobre la expansión del VIH/SIDA
}

Poco más de un mes y medio ha transcurrido desde que se llevó a cabo en Ginebra, Suiza, la $12^{a}$ Cumbre Internacional sobre el SIDA. Esta se viene celebrando desde 1985, cuatro años después de haberse descubierto el Síndrome de Inmunodeficiencia Adquirida. La Cumbre, de una semana de duración, tiene como propósito principal exponer los nuevos tratamientos, las nuevas técnicas para evitar el contagio entre mujeres embarazadas y sus hijos. De igual forma, se expusieron formas de terapias más eficaces y seguras, nuevo métodos para erradicar y controlar el virus y programas para desarrollar una vacuna efectiva, entre otras cosas. En la última Cumbre realizada se reveló que, en 20 años, cerca de 12 millones de personas han muerto a causa del SIDA desde que se detectó la enfermedad, y 31 millones son actualmente portadores del virus de inmunodeficiencia humana (VIH). Aunque se sabe de avances significativos en los países desarrollados, en países subdesarrollados —como Zimbabwe - el mal es cada día más catastrófico. Y es que éstos son los que están sufriendo en mayor medida las consecuencias de no tener los medios económicos y tecnológicos para llevar a cabo los tratamientos contra la enfermedad. "Estamos enfrentando un desastre y tenemos que adoptar una estrategia de asistencia de desastres" dijo, Stefan Germann, uno de los expertos que asistió a la conferencia.

Para entender la importancia de lo que aquí se discute, es necesario describir primero, a grandes rasgos, lo que es el VIH y cómo este causa SIDA. El VIH se caracteriza por el deterioro constante del sistema inmunológico, es decir, que desarticula la estructura de defensa del cuerpo humano y lo deja vulnerable ante cualquier enfermedad. Esto comienza cuando las células inmunológicas más esenciales, denominadas TCD4+ o "Linfocitos T", son descompuestas y eliminadas durante el proceso de infección del VIH. Sin la actividad normal de los "Linfocitos T", las demás células del sistema de defensa no realizan sus respectivas funciones.

Una persona no infectada por el VIH posee normalmente entre 800 y 1200 "Linfocitos T" por milímetro cúbico de sangre. La infección hace que el número de estas células se reduzca a menos de 200 por milímetro cúbico. Es entonces cuando la persona se vuelve particularmente vulnerable a las infecciones oportunistas (éstas son causadas por virus y otros gérmenes que provocan tos y diarrea prolongada, dificultad para tragar alimentos, pérdida de peso, etc.) y a los diferentes tipos de cáncer que caracterizan al SIDA'. El curso de la infección del VIH es peculiar porque hay un extenso período entre la infección inicial y la aparición de síntomas graves, por lo que la epidemia se expande entre las personas sin que éstas estén siempre conscientes de ello.

En los países industrializados, las terapias dan resultados positivos —en el sentido de retrasar las

I. "Cómo el VIH causa el SIDA", National Institute of Allergy and Infectious Diseases (NIAID), SIDA-HIV News, Argentina. 
manifestaciones más graves de la enfermedad-y los exámenes para detectar la presencia del virus son constantemente aplicados. Esto se ve favorecido por la existencia de campañas contra la enfermedad y de apoyo a las personas infectadas. Por el contrario, los países en desarrollo tienen una serie de limitantes que afectan la prevención y el combate contra el VIH/SIDA. Una de las más importantes es la falta de recursos económicos para abastecerse de los fármacos necesarios que impidan el progreso acelerado del virus. Para las economías del tercer mundo, el precio de las medicinas es prácticamente inalcanzable. El más asequible sobrepasa los 100 dólares, mientras que el tratamiento mensual asciende a casi 1,400 dólares.

En Africa, por ejemplo, donde el dinero es extremadamente insuficiente, hay 21 millones de personas infectadas por VIH; el 90 por ciento de esta población desconoce que es portadora del virus por falta de controles médicos. Según se prevé, casi todas estas personas morirán y la epidemia no se detendrá. Africa es uno de los lugares más pobres del mundo en donde no existen ni siquiera los cuidados más básicos. Los nuevos tratamientos contra el virus son desconocidos y la posibilidad de una vacuna contra el mismo es definitivamente más remota que en cualquier otro lugar. Las cifras son escandalosas en las ciudades africanas: el 70 por ciento de las mujeres embarazadas están infectadas, y más de un tercio de la población en las ciudades más grandes del continente son VIH positivo. El SIDA dejó huérfanos a 16 millones de niños en 1997 y los pronósticos señalan que la cifra aumentará sensiblemente cuando finalice el siglo $^{2}$. Para visualizar esta situación, basta con saber que existen zonas en Africa que han quedado desoladas por la mortandad causada por el SIDA.

La situación es distinta en los países desarroIlados, como Estados Unidos o España, donde es posible aplicar a los infectados todo tipo de medicamentos innovadores, y donde constantemente se está estudiando todo acerca de la enfermedad. En Estados Unidos, las minorías étnicas conforman el mayor número de afectados. De entre 7,200 casos de VIH, el 63 por ciento es de raza negra y el 5 por ciento, hispanos. Aunque actualmente el SIDA es la principal causa de muerte en Estados Unidos, entre personas de 25 a 44 años de edad, demás está decir que el control e investigación de la enfermedad es todo un movimiento científico, tecnológico, social y económico en esta potencia mundial.

En Centroamérica, la situación no deja de ser inquietante. Nicaragua es el país centroamericano con más bajos niveles de infección. El Ministerio de Salud de este país indicó recientemente que han fallecido unas 96 personas desde que la epidemia se detectó en Nicaragua (1987). Asimismo, se sabe que existen aproximadamente 323 personas contagiadas, de las cuales 160 son seropositivas y el resto portadores del virus. Honduras, por el contrario, es el país centroamericano más contaminado. Alrededor del 70 por ciento de los casos de SIDA se encuentran allí y la cifra se atribuye, en gran parte, tanto al comercio sexual en regiones como San Pedro Sula, como a los altos índices de analfabetismo y desinformación propios de este país ${ }^{3}$.

Guatemala es un caso, hasta cierto punto, similar al de El Salvador y Costa Rica. Se conocen 2,500 casos de SIDA, aunque no se descarta la existencia de más personas contagiadas, pues muchas desconocen su estado. En Guatemala, cerca del 90 por ciento de las personas infectadas no podrán obtener medicamentos ni tratamiento para controlar la enfermedad. El Ministerio de Salud de este país dijo, hace algunos meses, que sólo tiene la capacidad para atender a un 60 por ciento entre mujeres y menores. El resto de los afectados, hombres en su mayoría, no tendrán atención médica por falta de recursos de la institución. Guatemala necesitaría cerca de 5.3 millones de quetzales por mes para pagar el costo de los medicamentos que necesitan los infectados reportados en el último año.

En El Salvador, la información estadística es bastante inexacta. Un periódico matutino publicó, en julio pasado, algunas cifras acerca de la expansión del SIDA en El Salvador. El primer caso se informó en 1984 y, hasta la fecha, se han registrado 2,344 personas seropositivas y 2,221 con virus. En estos 14 años, 305 personas han muerto por la epidemia, 6 de las cuales fallecieron en 1998. Algunos de los infectados se encuentran internados

2. "Devastador SIDA", El País Digisal, No. 791, España, julio, 1998.

3. "Nicaragua con menor índice de SIDA en centroamérica”, La Prensa Honduras, No. 589, Honduras, diciembre, 1997. 
en la Unidad de VIH del Hospital Rosales. El cuidado que se les brinda a estos pacientes es con base en una "terapia antirretroviral" que ayuda a controlar el avance del virus y previene las infecciones oportunistas ${ }^{4}$.

Los medicamentos con que cuentan para tratar la enfermedad, no sólo en El Salvador sino en otros países centroamericanos, provienen de las donaciones de organismos no gubernamentales. instituciones de otros países o pacientes que tienen posibilidades económicas para contribuir en la lucha contra la enfermedad. Ciertamente, la práctica del reciclaje de medicamentos contra el

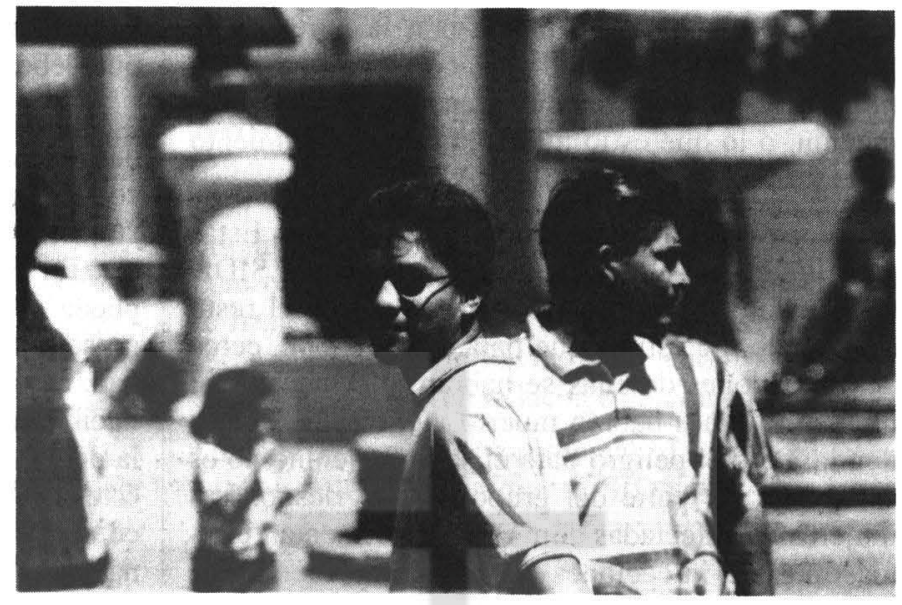
VIH es una forma de apoyo hacia los países en vías de desarrollo. La recolección la llevan a cabo personas independientes o algunas organizaciones de base comunitaria, que recolectan los medicamentos de personas que ya fallecieron o de gente cuyo tratamiento ha fracasado. Sin embargo, esto implica que los enfermos que reciben este beneficio tengan un suministro inestable, dado que no existe ningún lipo de supervisión y los riesgos de una dosificación incorrecta son enormes.

Algunas organizaciones dedicadas a la recolección de fármacos, como la AISD en New York y la Unión Positiva de Miami, tienen control acerca de las fechas de expiración y el momento en que se abre el medicamento, en la conlinuidad del suministro y en limitar el número de beneficiarios para garantizar el envío constante de medicamentos; no obstante, estos controles no siempre surten efecto. Por lo demás, en El Salvador se cuenta un poco con esa ayuda para los enfermos de VIH/ SIDA. Sin embargo, se conoce la existencia de 8 organizaciones que apoyan a los infectados y luchan contra la enfermedad. La Asociación entre Amigos, el Instituto de Estudios de la Mujer (Cemujer) y Fundasida, son algunas de ellas.

Evidentemente hay ciertos países más afectados por la epidemia que otros. De igual forma, hay grupos de personas que están más propensos que otros a adquirir la enfermedad. Aunque el SIDA no distingue raza, sexo o edad, es verídico que, al

contraerlo, no es para todos igual. Actualmente, el grupo de alto riesgo no sólo está conformado por homosexuales o personas con adicción a drogas intravenosas. Las mujeres forman también parte de este grupo. Ellas corren 18 veces más el riesgo de infectarse de SIDA que los hombres. Esto se debe a distintos factores. Ante todo, los biológicos: las mujeres tienen mayor superficie mucosa expuesta durante el acto sexual que el hombre, y el semen tiene mayor concentración de virus que el tluido vaginal. Por otra parte, la mucosa vaginal es mucho más frágil que el epitelio del pene. Igualmente alecla a las mujeres el hecho de que cualquier enfermedad venérea es una entrada para el contacto sanguíneo, por lo tanto, las enfermedades de transmisión sexual aumentan de 3 a 5 veces el riesgo de contraer el virus. Lo grave de esto es que muchas de estas enfermedades no producen síntomas en la mujer y, por ende, no son tratadas.

También existen lactores epidemiológicos, como las transfusiones sanguíneas, de las cuales algunas mujeres necesitan con alguna frecuencias. Asimismo son importantes los aspectos socioculturales que vuclven a la mujer vulnerable ante el contagio. Desde siempre se le ha inculcado a la mujer una especie de subordinación que le impide cuestionar a su parcja masculina sobre el comportamiento sexual que éste tenga. A la mujer se le enseña a conliar en su marido o compañero, aun cuando se sabe de un alto porcentaje de inlidelidad entre los hombres. Por igual, en muchas cultu-

4. "305 muertes por SIDA desde 1984", La Prensa Gráfica, julio, 1998, p. 10.

5. "Declaraciones médicas sobre el VIH en las mujeres", publicación de Laboratorios Filaxis. Argentina. agosto. 1997. 
ras se relaciona la ignorancia con la pureza y la inocencia sexual, actitud que conlleva a muchas mujeres a una alarmante situación de desinformación, o lo que es lo mismo, al desconocimiento de enfermedades como el SIDA.

El riesgo para las mujeres es grande. Estas constituyen un 12 por ciento de los casos de SIDA en Estados Unidos y un 50 por ciento en el resto del mundo. Se estima que para el año 2,000 , cerca de 14 millones de ellas se habrán infectado y que unos 4 millones habrán muerto víctimas de la epidemia. Pero el peligro para el sexo femenino no es solamente ser parte del grupo de alto riesgo. Las mujeres ya infectadas con VIH experimentan ciertos tipos de infecciones sintomáticas, además de las oportunistas típicas anteriormente mencionadas. Por ejemplo, sufren anormalidades menstruales: hipermenorrea, amenorrea, dismenorrea (éstos son trastornos y cólicos agudos). Los investigadores aún no están seguros de si estas irregularidades son producto de los cambios hormonales relacionados con el VIH o si se deben a las drogas utilizadas para combatir la infección. También pueden experimentar infecciones vaginales, que son normalmente comunes en las mujeres, pero que en el caso de una VIH positiva se vuelven más peligrosas y necesitan de terapias más agresivas de lo usual $^{6}$. Pese a esto y a otras situaciones, el VIH no es investigado en las mujeres de forma especial. Aún no se ha tomado en cuenta que, a pesar de que el tratamiento y el cuidado son casi los mismos para hombres y mujeres, ciertos aspectos del tratamiento son específicamente femeninos.

Ahora bien, hay un punto especialmente importante en la vida de una mujer portadora del virus o del SIDA: el embarazo. De aquí que los niños y niñas formen también parte del grupo de alto riesgo. El embarazo en una mujer puede resultar altamente peligroso para ella y para su hijo. Por naturaleza, el sistema inmunológico se deprime durante el embarazo. Luego del nacimiento, los niveles naturales de este sistema vuelven a su normalidad. Sin embargo, esto no es así necesariamente para una mujer con VIH/SIDA. Estas personas deben buscar cuidados prenatales especiales y discutir con su obstetra todas las precauciones que deben tomar.

Existe del 20 al 30 por ciento de probabilidades de contagiar el virus al feto durante el embarazo o el alumbramiento. También puede darse la "transmisión perinatal", es decir, durante la lactancia. En 180 días, desde el inicio del embarazo, se puede saber si el bebé está contagiado, pero aún no se puede determinar si desarrollará la enfermedad. El riesgo de transmisión madre-hijo puede reducirse hasta un 8 por ciento con la aplicación de la droga AZT en la madre. No se sabe si es porque éste reduce el nivel del virus o si es porque produce un tipo de intervención que reduce la contaminación. A los recién nacidos también se les puede suministrar AZT durante las primeras 6 semanas, sin que, hasta ahora, se reporten efectos secundarios. No obstante, la aplicación de esta droga implica altos costos?

Desde que la epidemia dio inicio en el mundo, más de 2 millones de niños han sido infectados por el virus a través de la madre, pero otros lo han contraído por el uso de drogas o relaciones sexuales prematuras. En El Salvador se informó que 26 niños estaban contagiados con el VIH en los primeros 6 meses del presente año. Estos niños son atendidos en el Hospital "Benjamín Bloom", y los hay desde recién nacidos hasta de 1 ó 2 años de edad. Sus madres son mayoritariamente adolescentes abandonadas por su pareja ${ }^{8}$. Un informe, publicado en 1997 por el Programa Conjunto de Naciones Unidas sobre el VIH/SIDA, explicaba que para el año 2,001, el SIDA puede aumentar la mortalidad de los lactantes hasta un 75 por ciento, y la mortalidad de niños menores de 5 años hasta un 100 por ciento en los países del mundo más afectados por la enfermedad".

Sin duda, los niños y las niñas son las víctimas más preocupantes en esta situación, pues no tendrían que estar infectados para sufrir las consecuencias. Muchos han quedado huérfanos y seguirán quedando al paso de la enfermedad. Aunque en la última Conferencia Mundial se revelaron adelantos y programas para reducir la contamina-

6. "La mujer HIV positiva". SIDA-HIVNews, Argentina. 1997.

7. "El embarazo y HIV", SIDA-HIV News, Argentina. 1997.

8. "Alarma por el incremento de niños infectados por SIDA", El Diario de Hoy, julio, 1998.

9. "Un nuevo informe aporta pruebas perturbadoras de que los niños de todo el mundo sufren de forma creciente la amenaza de la epidemia de VIH/SIDA", comunicado de Prensa de UNAIDS, junio, 1997. 
ción entre la madre y su hijo, se ofrecieron alternativas para la lactancia y otros nuevos caminos para controlar el virus; sin embargo, los niños de los países subdesarrollados no podrán disfrutar de estos beneficios. Nuevamente, en Africa subsahariana cerca del 90 por ciento de niños, de los 9 millones que actualmente se consideran, han perdido a su madre por la enfermedad.

Toda esta información expuesta aqú tiene el único propósito de generar conciencia sobre el problema, del cual los salvadoreños no estamos - ni podemos estar - al margen. Dar la espalda al mismo o poner las manos sobre los ojos es el peor error que se puede cometer. Equivocadamente se cree que ignorando la situación ésta va a desaparecer, sin embargo, lo único que se consigue es que ésta se expanda "silenciosamente".

Por otro lado, es esencial dar educación sexual a los adolescentes por parte de los centros de estudio $y$, especialmente, en el hogar. Proponer una abstinencia total es definitivamente inútil, lo mejor es explicar, prevenir y educar correctamente sobre las relaciones sexuales, para que los jóvenes asuman por su cuenta la necesidad de ser responsables al respecto. Se cree que el que los adolescentes conozcan sobre el sexo y los métodos anticonceptivos, estimula la iniciación de las relaciones sexuales a más temprana edad. Por el contrario, los adolescentes que todavía no tienen experiencia sexual pueden retrasar su iniciación al conocer las consecuencias. Entre los adolescentes que ya son sexualmente aclivos, el mayor conocimiento produce que ellos desarrollen el uso de métodos como el preservativo y a que realicen prácticas sexuales más seguras.

Es legítimo pensar que, por ser El Salvador un país subdesarrollado, que tiene que afrontar todos los aspectos ya mencionados sobre la epidemia, lo más sensato es prevenir el contagio. La salud personal es responsabilidad de cada uno, pero la gra- vedad de la situación exige pensar en función colectiva. Se necesita ampliar conocimientos sobre el tema, crear una campaña fuerte y contundente que fomente preocupación y atención sobre el asunto. Se necesita mucha mayor presión y difusión de información respecto a la enfermedad en comunidades, zonas rurales, centros de estudio, centros de trabajo, etc. Hay que informar a la gente haciendo hincapié en lo fácil que es contraer el virus y en los métodos de prevención. Ese podría ser un buen inicio en la lucha contra la enfermedad.

Uno de los grandes problemas de la comunidad salvadoreña es creer que el SIDA sólo puede ser contraído por personas promiscuas. Se tiene la idea equivocada de que los índices de VIH/SIDA son bajos, ello obedece al descuido y la poca profundidad con que los distintos sectores públicos y privados involucrados enfocan el tema. Una vez más, el problema no es simple. Ejemplificando: al menos el 50 por ciento de las trabajadoras del sexo en El Salvador son portadoras del virus. Si se piensa en la cantidad de hombres, casados y con vidas sexualmente activas, que hacen uso de sus servicios sin el más mínimo sentido de protección, se puede tener una idea de lo que realmente está pasando en nuestro país.

Se dice que antes de 10 años no habrá una vacuna contra el VIH/SIDA. Esto deja a la prevención como la única alternativa realista para los países en desarrollo. Entre más documentada e informada se encuentra la sociedad, más fácil será conseguir que la epidemia se controle, pues detenerla es por ahora imposible. La responsabilidad es de todos por igual, pero hay quienes pueden tomar medidas contundentes y eficaces: aquéllos que tienen el poder de infurmación, de educación, de difusión. De ellos depende, en principio, que se inicie una lucha efectiva contra la epidemia.

\section{Claudia Huete Guzmán}

